\title{
The Internet and Prospective Engineers: Results Analysis for Studies Conducted During the Pandemic
}

\section{Internet e ingenieros potenciales: análisis de resultados para estudios realizados durante la pandemia}

\author{
Rimma A. Soloveva* \\ Arctic State Agrotechnological University, Yakutsk, Russian Federation. \\ ORCID: http://orcid.org/0000-0002-3616-7932 \\ Vladimir P. Barakhsanov \\ .K. Ammosov North-Eastern Federal University, Yakutsk, Russian Federation. \\ ORCID: http://orcid.org/0000-0003-2054-2555 \\ Afanasy R. Batorov \\ Arctic State Institute of Culture and Arts, Yakutsk, Russian Federation. \\ ORCID: http://orcid.org/0000-0003-2061-597X \\ Alena V. Kibalnik \\ Irkutsk State University, Irkutsk, Russian Federation. \\ ORCID: http://orcid.org/0000-0003-1527-439X \\ Natalya A. Moskalyonova \\ Admiral Nevelskoy Maritime State University, Vladivostok, Russian Federation. \\ ORCID: http://orcid.org/0000-0002-0893-644X
}

Received 06-12-20 Revised 07-25-20 Accepted 09-13-20 On line 09-22-20

*Correspondence

Email: rimma.a.soloveva@bk.ru
Cite as:

Soloveva, R.A., Barakhsanov, V.P., Batorov, A.R., Kibalnik,
A.V., Moskalyonova, N.A. (2020). The Internet and
Prospective Engineers: Results Analysis for Studies
Conducted During the Pandemic Propósitos y
$\begin{array}{llll}\text { Representaciones, } 8 & \text { (SPE2), e714. Doi: } \\ \text { http://dx.doi.org/10.20511/pyr2020.v8nSPE3.714 }\end{array}$




\section{Summary}

The relevance of the study is justified by transition to distance learning that modifies the learning methods and principles during the pandemic to conform to remote training needs of students majoring in Land Management and Cadastres at Arctic State Agrotechnological University (ASAU). of the Republic of Sakha (Yakutia). The study objective was to substantiate the interaction between ASAU students and teachers in remote training organization within the pandemic period using network technologies. The study monitored the educational process dynamics during the pandemic. The study results evidence that during the pandemic, a particular priority in educational process arrangement at ASAU was given to enhancing the professional readiness of students and teachers and building up their competence in organizing their professional activities using the Internet in compliance with the latest requirements of the Federal State Educational Standards. The reference and experimental groups were sampled based on students' interviews during the transition to remote access Internet-based educational process. The practical implications of the study lie in identifying the distinctive features of teachers' and students' educational activities at ASAU during the pandemic. These results can be adapted and implemented in the system of prospective engineers' training in other regional universities in the north-east of Russia.

Keywords: Distance Learning; the Internet Network; Remote Access; Information Competence.

\section{Resumen}

La relevancia del estudio se justifica por la transición al aprendizaje a distancia que modifica los métodos y principios de aprendizaje durante la pandemia para ajustarse a las necesidades de capacitación remota de los estudiantes que se especializan en Administración de Tierras y Catastros en la Universidad Agrotecnológica del Estado del Ártico (ASAU). de la República de Sakha (Yakutia). El objetivo del estudio fue fundamentar la interacción entre estudiantes y profesores de ASAU en la organización de capacitación remota dentro del período de la pandemia utilizando tecnologías de red. El estudio monitoreó la dinámica del proceso educativo durante la pandemia. Los resultados del estudio evidencian que durante la pandemia, se dio una prioridad particular en la organización del proceso educativo en ASAU a mejorar la preparación profesional de estudiantes y maestros y desarrollar su competencia en la organización de sus actividades profesionales utilizando Internet de acuerdo con los últimos requisitos de la Estándares educativos del estado federal. Los grupos de referencia y experimentales fueron muestreados en base a las entrevistas de los estudiantes durante la transición al proceso educativo de acceso remoto basado en Internet. Las implicaciones prácticas del estudio radican en identificar las características distintivas de las actividades educativas de los profesores y los estudiantes en ASAU durante la pandemia. Estos resultados se pueden adaptar e implementar en el sistema de formación de futuros ingenieros en otras universidades regionales en el noreste de Rusia.

Palabra clave: Aprendizaje a Distancia; La Red de Internet; Acceso Remoto; Competencia Informativa.

\section{Introduction}

Development of the information society while changing the nature of living environment and professional activity of an individual has foregrounded the problem of building up the information and communication competence of prospective engineers as the basis for their preparation for professional activity in the new educational environment. The relevance of implementing distance learning supported by e-learning is confirmed by a number of documents stipulating the state policy in development and use of information and communication technologies: "The Strategy of information society development in the Russian Federation for 2017-2030", "The Strategy of IT industry development in the Russian Federation for 2014-2020 and projected up to 2025", etc. 
The modern experience in e-learning implementation facilitated by the Internet at an agrotechnological university evidences for the need for cooperation between teachers and students in distance learning. Besides, the importance of teachers' and students' joint efforts in using modern information technologies in the educational process is enhanced, as only joint activities enable successful managing a wide variety of applied software and the problems that arise in training of future agro-industrial complex specialists majoring in "Land Management and Cadastres".

The current evolution stage of the information society and education is specified by the need of mastering high-tech computer tools that shall be comprised in high-qualified engineers training at universities. For their future successful professional activities, in accordance with the Federal Educational Standards 3++, bachelor engineers are to master an important professional competence in rapid search, analysis and public presentation of research results using computer technologies. Moulding this competence will be a success when based on using modern educational technologies and computer hardware, the Internet, and on implementing new methods and practices into a professional activity area (Barakhsanova, Danilova, 2018; Vlasova, 2010; Solovyova, 2018).

One can note that Arctic State Agrotechnological University (ASAU) of the Republic of Sakha (Yakutia) runs its activities with respect to changes in economic, social, and cultural development of Yakutia related to northern natural and climatic environment, the traditional economy and life support systems, and material and spiritual culture influencing mentality and ethnic identity of young people. It determines the ethnic and cultural uniqueness of bilingual students and foregrounds the problem of social requirement for human resourcing to provide for sustained development of agriculture, forestry and land management. It is a particularly challenging problem under conditions of bilingualism in educational process and poor information competence of students, especially of first-year ones.

The Republic of Sakha (Yakutia) is located beyond the Arctic circle, its area being 3,103 sq.km. and population density - 0.3 person per $1 \mathrm{sq}$. km. During the pandemic, all students were sent to their residence communities. Among difficulties encountered in technological aspect of facilitating the educational process via the Internet, the students had to cope with a low Internet connection speed, scheduled power outages, difficulties in installation of the software proposed for educational process, and unreadiness of some of them to shift to distance learning.

In view of specific area features, in particular, its location in the north-east of Russia, the use of distance education technologies and network educational patterns in the educational process is focused on active development of information competence and mastering practical experience in using modern information and network technologies.

\section{Material and Methods}

Nowadays, the Internet in education is used as a communication tool. Historically, publications in virtual communication have been prefaced by research reviews in psychological aftereffects of working practice computerization (Tikhomirov, Gurieva, 1986). Notify that in present-day education, the use of Internet resources is significant. In educational Internet milieu, students are motivated to create their own web-pages loading up texts, audio and graphic images, and to use electronic resources available in the network.

In higher education development, the importance of University electronic informational and educational environment is critical; it has become a factor of outstanding significance in improving the efficiency of future specialists training (Danilov, Barakhsanova, 2003; Slobodchikova, Barakhsanova, Danilova, 2007; Solovyova, 2017). 
The problems of regional universities in establishing and developing the electronic educational environment, implementing information technologies and software in teachinglearning process are focused on in papers by E. A. Barahsanova (Barahsanova, 2015), T. Zh. Bazarzhapova (Bazarzhapova, 2008), T. S. Bazarov and R. A. Solovyov (Bazarova, Solovyov, 2018); L. N. Ruliene (Reliene, 2013), N. B. Sekulich (Sekulich, 2017); (Batorov, 2012), etc. Reviewing theoretical sources has revealed that development of distance education content and its organization for ASAU students in emergency cases (the pandemics) have been understudied.

Discussion of virtual reality mechanisms and nature in human sciences was presented in the paper by domestic authors as far back as the early 90's; thus, in the article "Self-presentation strategies in the Internet and their relation to real identity" the concepts of "computer virtual reality" and "virtualization" are considered. The authors assert that virtualization is transition of principal activities into the virtual network space (Belinskaya, Zhichkina, 2004). In this regard, it should be highlighted that establishing the information competence in students in modern higher education context is a pressing challenge.

In her paper, the foreign researcher Elizabeth M. Reid claims that e-learning is regarded as a special cultural education that does not directly duplicate the actual social environment (Reid, 1994). Judith S. Donath stipulated that information and network communication and the Internet network are technologies that facilitate e-learning (Donath, 1997).

Currently, as Tony Bates noted in his book, online learning is increasingly affecting classroom or campus teaching, but more importantly, it is leading to new models or designs for teaching and learning. As we move from teaching in the classroom to teaching online, we shift the learning environment. Thus, we shall develop models where the learning method has been pre-adapted to teaching environment (Bates, 2019).

According to classification by A. Kaplan and M. Haenlein, online learning can be classified by the time factor. Students can learn at their own pace, according to their own schedules (asynchronous distance learning), or simultaneously (synchronous distance learning) (Kaplan, Haenlein, 2016). Tallent-Runnels et al. explain that "synchronous online courses are tailored in such a way that all students are online and communicate simultaneously, while asynchronous online courses allow students to work even if no one else is also logged in" (Tallent-Runnels, Thomas, Lan, Cooper, Ahern, Shaw, \& Liu, 2016).

Papers by teachers of North-Eastern Federal University published in foreign editions touch upon issues of training teachers for the north-east of Russia based on distance learning with respect to material and technical equipment and software available in local educational institutions (Barakhsanova, Varlamova, Vlasova E. Z., Nikitina, Prokopyev, Myreeva, 2018; Barakhsanova, Golikov, Sorochinsky, Lukina, Ilina, Nikitina, 2018); development and evergrowing use of modular training programs for teachers and educators due to organization and implementation of network education in the area (Barakhsanova, Golikov, Sorochinsky, Lukina, Ilina, Nikitina, 2018; Barakhsanov, Barakhsanova, Golokova, Kronnikov, 2017; Barakhasanov, Barakhasanova, Olesov, Prokopyev, 2018).

At scientific, methodological and practical levels these papers evidence that the use of elearning in teaching at a higher education institution raises requirements to teachers' qualifications and training. This process requires a consistent and adaptive teachers' training to enable their innovative technological decision-making in the digital educational environment; teachers' motivation for mastering new digital methods and techniques of digital educational resources; preparation and implementation of adaptive professional development programmes focused on distance learning delivery using modern and forever changing digital technologies. 
At ASAU, a special role is assigned to a University teacher whose professional activities are immediately related to the training process of future agricultural specialists, including specialists "Land Management and Cadastre" for the Republic of Sakha (Yakutia). It is the teacher who selects online learning methods and their significance in the educational process to enhance the students' information competence.

To solve the tasks above, the following research methods were used: analysis, generalization and systematization of experiment outcomes using questionnaires - to identify the level of engagement and the degree of communication in the Internet. Results' reliability and validity are facilitated by using the fixation method and the empirical analysis method.

To evaluate a textual question with multiple choice, the equilibrium evaluation system is used. The answer weight is determined by the formula: $\mathrm{W}=\mathrm{B}_{\max } / \mathrm{N}=100 \% / \mathrm{N}$, where $B_{\max }$ is the maximum score for an answer to the question, and $N$ is the total number of answers to the question. The result is calculated as follows: for every correct answer the weight is added, and for every wrong one the weight is deducted. $\mathrm{W}_{\text {total }}=\sum W_{\text {right }}-\sum \mathrm{W}_{\text {wrong }}$ where $\mathrm{W}=\mathrm{W}_{\text {wrong }}=\mathrm{W}_{\text {right }} ; \mathrm{W}_{\text {right }}$ is the score for the right answer (the answer is regarded as right if it is correct and has been selected and a wrong answer has not been selected instead). $\mathrm{W}_{\text {wrong }}$ is the score for the wrong answer (the answer is regarded as wrong if it is incorrect and has been selected and the right answer has not been selected instead). Then, this sum is normalized (the score range $[-100 ;+100]$ is brought to the range $[0 ;+100])$ :

$$
\mathrm{W}=\mathrm{W}_{\text {total }}+100 / 2 \text {. }
$$

Answering multiple choice questions is similar to answering questions with a single true answer. The maximum score $(100 \%)$ is assigned to all correct answers, and solely to them.

Consider next calculating weight for an example where 4 answer variants comprise 2 correct and 2 wrong ones. The selected answer to this question included 1 correct and 1 wrong one. The weight of each answer to the question: $\mathrm{W}=\mathrm{B}_{\max } / \mathrm{N}=100 \% / 4=25 \%$. The calculation proceeds as follows: $\mathrm{W}_{\text {total }}=25 \%$ (for a selected correct answer) $+25 \%$ (for a non-selected wrong answer) $-25 \%$ (for a non-selected correct answer) $-25 \%$ (for a selected wrong answer) $=0 \%$.

\section{Results}

The results analysis of questionnaires completed by ASAU students and teachers, the Republic of Sakha (Yakutia), manifests that the Internet is a universal communication facility wherein a variety of students' educational activities are engaged. The respondents noted that the use of the Internet lead to implementing the following activity types in the educational process: 1) communicative activities, i.e. e-mails, chats, videoconferences, mailing lists, etc.; 2) educational activities, i.e. reading books, online press, searching for specific educational information or finding out the current news, distance education, etc.; 3) gaming activities, i.e. traditional sports games such as chess, checkers, Oriental games, etc., as well as gambling with real partners via the Internet.

Three test question sets were compiled for three extensive studies. The first study covered first-year students. Their questionnaire included 21 questions focused on a comprehensive covering all aspects of Internet use: user activity, computer games, Internet user general profile, 
as well as distance learning methods in the educational process in online-based environment. The study results offer insight into Internet use by first-year students in the basic academic disciplines.

It was followed by the second study among 300 students related to 5 ASAU departments. For this study, the questionnaire was improved, and it comprised 30 sociological and psychological questions. It included questions dealing with students' user activity and its content, awareness of Internet risks, Internet resources, and online teaching methods. Besides, the questionnaire was developed engaging certain methods, such as the Internet Addiction Test by Kimberly Young, the method for determining the emotional perception of the Internet. It also comprised a number of open questions providing for a qualitative analysis of attitude to the Internet.

The third study was ASAU teacher-centered. Within this study, 50 teachers were interviewed, who both use and do not use the Internet. The test questionnaire included 30 questions aimed at eliciting teachers' opinions of Internet technologies use by students, finding out the degree of parents' control of Internet use by their children and teachers' general awareness of the effect the modern technologies create in young people's health and behaviour. Moreover, teachers' questionnaire comprised questions dealing with: teacher's activity in the Internet and its content, the notion of students' purposes for Internet use, the motivation for Internet use, the assessment of Internet freedom, emotional perception of the Internet, etc. This test questionnaire, as well as the one for students, included a number of open-ended questions to determine teachers' negative experiences when using the Internet. The analysis of survey results revealed the interesting and unique data that enabled us to conduct a comparative analysis of peculiar features in Internet use and perception by students and teachers. Due to the selected survey form, we outlined the role of Internet use for educational purposes and were enabled to compare views of Internet resource use shared by teachers and students.

We noted a fairly high percentage of interest in using global Internet resources in ASAU educational process. Students' attitude to Internet resources can be examined by the level of their interest in seeking certain distance learning skills, as well as by outlining the areas the most attractive for them. To identify them, the students were asked special questions, where they were asked to specify the application area of Internet resources and technologies that they would like to improve and develop.

All students would like to take part in project development groups related to network technologies use with free software applications. $72 \%$ of students select video content processing as their main activity area, namely, editing, creating streams and screencasts. Web programming ranked second $-25 \%$, and printed information layout and design ranked third. These results evidence for presence of motivation in students to use Internet technologies in their future professional activities.

$85 \%$ of experiment participants prefer using modern educational technologies, especially Internet resources in their professional activities. The percentage of survey answers obtained from teachers and students about their preferences in network technologies distributed as follows: developmental learning (27\%), classic (24\%) and information (49\%) technologies. A significant number of respondents put a stress on the efficiency of using Internet resources and technologies.

To find out whether the students were ready to use new training aids, some questions were asked about the advantages of online learning in academic disciplines. Using the questionnaire, we tried to identify the needs of teachers and students in using certain Internet resources and technologies. The survey diagnosed that $65 \%$ of teachers find it necessary to improve the Internet information competence. In our opinion, it is due to active network technologies implementation into all areas of students' activities. Despite a widespread occurrence of self-study courses on software use, they are expressly insufficient, $35 \%$ of teachers mentioned the necessity to study software applications use in their professional activities. 
On average, the Internet usage indicators by teachers and students improved by $69.7 \%$ and $39.9 \%$, respectively. The generalized tests analysis is an indicative of the fact that Internet resources and communication are so rapidly embedded into educational that this process can hardly be researched or examined properly by teachers. It should be noted that the subject field of research in e-learning shall be started while preparing student for their professional activities in response to education informatization.

Next, we checked over attendance of Moodle virtual learning environment (http://moodle.ysaa.ru) by ASAU students and teachers. Moodle is very convenient to monitor activities of both teachers and students; it facilitates class delivery by subjects, on-line testing, and provides access to teaching and learning aids at the library. To identify the level of user skills and tracking attendance, the quality analysis of electronic documents (student registers) in Moodle was done to demonstrate to teachers the level of students interest in learning via the University's website. According to the data, in the period from 13.04.2020-13.05.2020 (per one month), the site recorded 4078 students and 193 faculty members. The attendance dynamics is shown in Fig. 1.

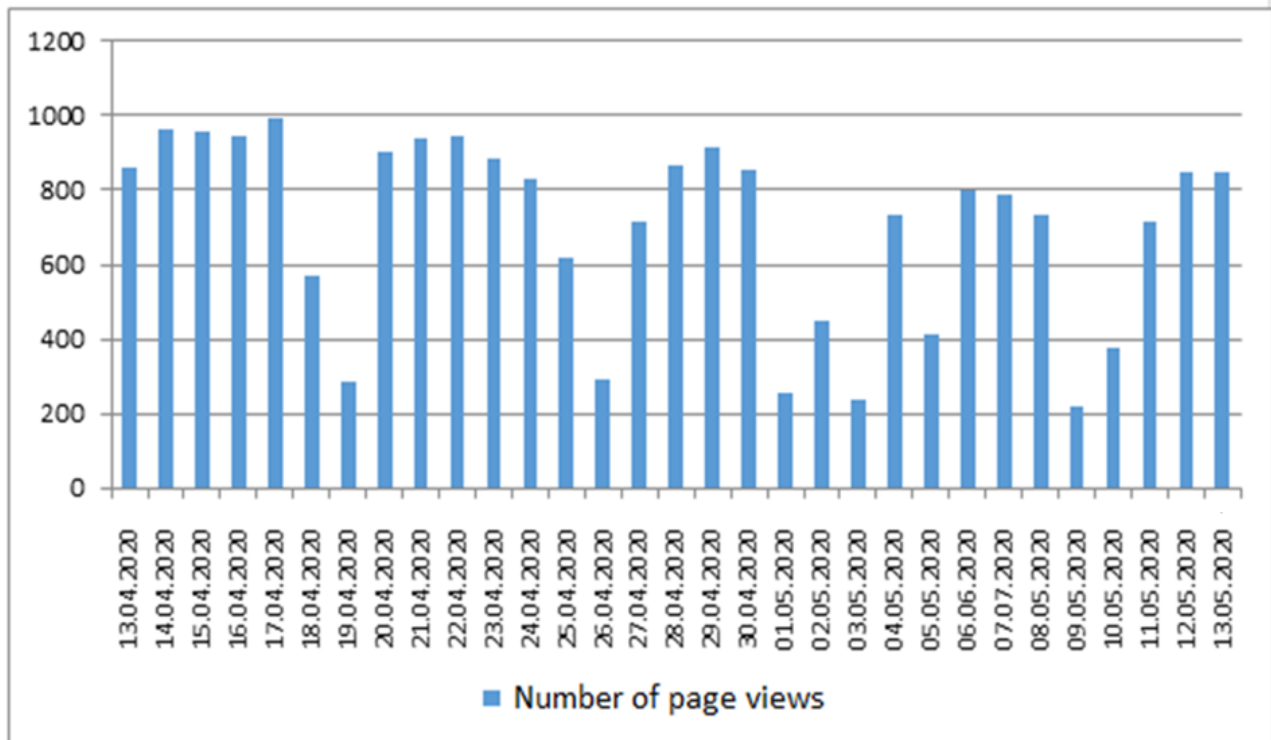

Figure 1. Moodle site traffic statistics per one month (13.04.2020-13.05.2020).

Many students visit the site to view no more than a single page that is the home page of the site. Most visitors log in purposefully and not accidentally. Note that ASAU students are leavers of rural schools, and come from remote (Arctic) areas (uluses) of the Republic. Due to the peculiarities of our educational environment in the Republic, there is a special need for distance education in remote areas. However, in the deep countryside, not everyone eager to study has an available computer with access to the Internet.

\section{Discussion}

Today, there are quite a lot of Internet platforms to provide video communication, and most of them are paid. In higher education institutions of the Republic of Sakha (Yakutia) in March-June 2020, teachers actively used free Zoom platform for delivering online classes and events. It has a simple control algorithm and an option of simultaneous connecting a large number of participants. Zoom Cloud Meetings is a particularly popular tool for holding on-line video conferences and video webinars in high-definition format in real time. Zoom supports integration with Moodle, it enhances and expands classes with powerful collaboration tools, including video breakout rooms, 
multi-sharing, polling, and group chats. Tracking attendance and attentiveness shows teachers who are interested in learning via the Internet.

It was found that while preparing the prospective engineers for their professional activities at ASAU based on using Internet technologies, teaching and learning materials for delivering classes shall be supplemented with up-to-date electronic resources. The current difficulties in preparing electronic resources and didactic materials for online learning have been outlined. Patterns of teaching-learning interaction have been specified in view of improving the content of educational programs for future engineers based on Internet technologies and Internet resources.

The study analysis shows that online learning will contribute to increase of University's competitiveness and to growth of the number of undergraduates and postgraduates enrolled onthe-job. Implementing new technologies in education will cater for preparation of electronic textbooks with multimedia components and engaging external electronic resources, for using cloud technology to develop smart-textbooks facilitated by technological innovations and Internet resources.

Thus, it should be noted that it is necessary to substantiate and develop the concept and innovative model of scientific and methodological and information technology provision of remote access to training based on the use of information and communication technologies and electronic educational resources, including Internet resources.

\section{Conclusion}

Complex events of 2020 due to COVID-19 spreading accompanied by transition to distance learning gave a big boost to e-learning development and online communication at ASAU. It is distance learning that provides people who live in remote localities or those who can not attend full-time classes for some reasons with access to education. At present, the University communicates with teachers and tutors mostly via the distance teaching system: Moodle, on-line tools: Zoom, Skype and e-mail.

Distance education students seek to have strong motivation and strict self-discipline, a developed willpower, responsibility and self-organization that are also vital tools to maintain the required pace of learning on their own without an external control, and not all students succeed in it. Each person has own rhythm and speed of new information perception. In on-line learning, you can always get back to a topic, for example, re-watch a recorded lesson, review the theoretical material and consolidate your knowledge. This opportunity is an essential advantage, as it improves chances of successful training completion.

Summarizing, it is important to note that the compelled transition to distance learning during the self-isolation period enabled each teacher to review his/her competences in information and communication technologies and to improve his/her skills and capacities by self-education, trial and error method, to create an individual teaching system in a remote format, and to extend his/her pedagogical opportunities due to using a wide range of modern digital electronic resources in educational activities.

\section{References}

Barakhasanov, V.P., Barakhasanova, E.A., Olesov, N.P., Prokopyev, M.S. (2018). E-learning system application for physical education and sports specialist training. Theory and Practice of Physical culture, 7, 4

Barakhsanov, V.P., Barakhsanova, E.A., Golokova, V.S., Kronnikov, N.D. (2017). Ethniceducational aspects of intellectual games development process in Sakha (Yakutia) Republic. Theory and Practice of Physical Culture, 7, 34. 
Barakhsanova, E.A. (2015). Scientific and methodological support of Masters' training under network learning. Scientific and methodological electronic journal "Concept", 26, 106110 .

Barakhsanova, E.A., Golikov, A.I., Sorochinsky, M., Lukina, T., Ilina, E., Nikitina, E.V. (2018). Implementation of the master program "corporate e-learning" in the online interaction of Russian universities. Espacios, 39(20), 36.

Barakhsanova, E.A., Varlamova, V.A., Vlasova, E.Z., Nikitina, E.V., Prokopyev, M.S., Myreeva, A.N. (2018). Vocational training of school teachers in Yakutia's universities through the principle of regionalization (case study of the methodology of teaching natural science to prospective teachers). Espacios, 39(20), 35.

Barakhsanova, E.A., Danilova, A.I. (2018). Implementation of e-learning in a digital educational environment. The azimuth of scientific research: pedagogy and psychology, 7(25), 38-40.

Bates, T.A.W. (2019). Teaching in a Digital Age - Second Edition. Vancouver, B.C.: Tony Bates Associates Ltd.

Batorov, A.R. (2012). Multimedia applications as an effective means of supporting the educational process in information and educational environment of a University of Culture. Information and communication technologies and electronic resources in the system of cultural and civilizational transformations: experience and problems of their using in higher education institutions of culture and arts, 208-214.

Bazarova, T.S., Solovyova, R.A. (2018). Pedagogical conditions for formation of ICT competence in future engineers at a regional University. The azimuth of scientific research: pedagogy and psychology, 3(24), 230-233.

Bazarzhapov, T.Zh. (2008). Use of online resources in professional activity. Herald of Buryat State University, 15, 10-13.

Belinskaya, E.P., Zhichkina, A.E. (2004). Strategies of self-presentation in the Internet and their relation to real identity. Retrieved from: http://flogiston.ru/articles/netpsy/strategy

Danilov, D.A., Barakhsanova, E.A. (2003). Formation of information basis of specialist's activity in the system of professional pedagogical education. Informatics and education, 5, 102.

Donath, J.S. (1997). Identity and deception in the Virtual community.

Kaplan, A.M., Haenlein, M. (2016). Higher education and the digital revolution: About MOOCs, SPOCs, social media, and the cookie monster. Business Horizons, 59(4), 441-450.

Reid, E.M. (1994). Cultural Formations in Text-Based Virtual Realities.

Ruliene, L.N. (2013). Educational process in modern University: features, contradictions, development trends: monograph. Ulan-Ude: Buryat State University Publishing House.

Sekulich, N.B. (2017). Formation of ICT competencies in University students during digital revolution. Pedagogical magazine, 7(2A), 302-314.

Slobodchikova, A.A., Barakhsanova, E.A., Danilova, A.I. (2007). Scientific and methodological bases of development of electronic educational tools: monograph. Moscow: Ministry of Education of Moscow Region, State Educational Institution of Higher Vocational Education "Moscow State Regional University".

Solovyova, R.A. (2017). Electronic educational resources. Kinds. Structures, technologies. Review. BGARF, 2(40), 284-287.

Solovyova, R.A. (2018). Electronic information and educational environment of a regional University as a factor of improving education quality. Higher education today, 12, 25-30.

Tallent-Runnels, M.K., Thomas, J.A., Lan, W.Y., Cooper, S., Ahern, T.C., Shaw, S.M., Liu, X. (2006). Teaching courses online: A review of the research. Review of Educational Research, 76(1), 93-135.

Tikhomirov, O.K., Gurieva, L.P. (1986). Psychological analysis of labor activity, mediated by computers. Psychological journal, 7(5), 13-26.

Vlasova, E.Z. (2010). Didactic potential of e-learning technologies. Universum: Herald of the Herzen University, 1, 113-116. 